\title{
Gold nanodot-based luminescent sensor for the detection of hydrogen peroxide and glucose $\dagger$
}

\author{
Yen-Chun Shiang, ${ }^{a}$ Chih-Ching Huang* ${ }^{b}$ and Huan-Tsung Chang $* a$ \\ Received (in Cambridge, UK) 29th January 2009, Accepted 31st March 2009 \\ First published as an Advance Article on the web 1st May 2009 \\ DOI: $10.1039 / b 901916 b$
}

We unveil a new luminescent assay using 11-mercaptoundecanoic acid-bound Au nanodots (11-MUA-Au NDs) for the highly selective and sensitive detection of hydrogen peroxide and glucose, based on luminescence quenching.

Hydrogen peroxide $\left(\mathrm{H}_{2} \mathrm{O}_{2}\right)$ is involved in many chemical, biological, pharmaceutical, clinical, environmental, and food processes. ${ }^{1}$ Of the many analytical techniques that have been reported for the determination of $\mathrm{H}_{2} \mathrm{O}_{2}$, optical (absorption, chemiluminescence, and fluorescence) and electrochemical (amperometry) approaches are the most popular. ${ }^{2,3}$ Although these methods have the practical advantages of sensitivity, rapidity, and/or specificity, they also have several disadvantages, such as difficult or time-consuming operating procedures, the need for expensive reagents, and/or the presence of serious matrix effects. Thus, rapid, accurate, reliable, sensitive, and cost-effective approaches for the detection of $\mathrm{H}_{2} \mathrm{O}_{2}$, and hence various enzyme substrates (analytes), are in great demand for application to medical diagnostics.

In this study, we developed a new sensor for the determination of glucose vicariously through the detection of $\mathrm{H}_{2} \mathrm{O}_{2}$ induced luminescence quenching of luminescent 11-mercaptoundecanoic acid-bound Au nanodots (11-MUA-Au NDs). We investigated the impact of $\mathrm{pH}$ and temperature on the sensitivity of the system toward glucose, and validated its practical applicability through the determination of glucose in a serum sample.

Scheme 1 illustrates the process of $\mathrm{H}_{2} \mathrm{O}_{2}$-induced luminescence quenching of 11-MUA-Au NDs $(2.0 \pm 0.3 \mathrm{~nm})$. In the presence of $\mathrm{H}_{2} \mathrm{O}_{2}, 11-\mathrm{MUA}$ units that are bound to $\mathrm{Au}$ NDs through $\mathrm{Au}-\mathrm{S}$ bonding are readily oxidized to form an organic disulfide product (RS-SR) ${ }^{4}$ As a result, fewer 11-MUA molecules are bound to the Au NDs, leading to reduced luminescence. The proof-of-concept experiment was first tested by measuring the luminescence of solutions of $10 \mathrm{mM}$ sodium phosphate ( $\mathrm{pH}$ 5.0) containing 11-MUA-Au NDs $(100 \mathrm{nM})$ in the absence and presence of $\mathrm{H}_{2} \mathrm{O}_{2}(10 \mathrm{mM})$. Fig. 1 displays both the absorption and luminescence spectra of the 11-MUA-Au ND solutions in the absence and presence of $\mathrm{H}_{2} \mathrm{O}_{2}$. Although the presence of $\mathrm{H}_{2} \mathrm{O}_{2}$ induced only a slight decrease in the absorbance at $375 \mathrm{~nm}$, it caused a significant decrease in the luminescence at $522 \mathrm{~nm}$. By monitoring the

\footnotetext{
${ }^{a}$ Department of Chemistry, National Taiwan University, 1, Section 4, Roosevelt Road, Taipei, 106, Taiwan.E-mail: changht@ntu.edu.tw; Fax: +886-2-33661171; Tel: +886-2-33661171

${ }^{b}$ Institute of Bioscience and Biotechnology, National Taiwan Ocean University, Keelung, 20224, Taiwan.E-mail: huanging@ntou.edu.tw; Tel: $+886-2-24622192$ ext. 5517

$\dagger$ Electronic supplementary information (ESI) available: Experimental and additional figures. See DOI: 10.1039/b901916b
}

decrease in luminescence, we found that the $\mathrm{H}_{2} \mathrm{O}_{2}$-induced luminescence quenching of the 11-MUA-Au NDs reached completion within $10 \mathrm{~min}$ (see the inset b in Fig. 1b). Our observations suggest that luminescence detection is more sensitive than absorption detection when using these 11-MUA-Au NDs. The intensities of static light scattering of the 11-MUA-Au NDs (100 nM) in the absence and presence $\mathrm{H}_{2} \mathrm{O}_{2}(10 \mathrm{mM})$ were determined to be $320( \pm 35)$ kcps $(n=5)$ and $305( \pm 43) \mathrm{kcps}(n=5)$ by using a particle size analyzer (Zetasizer Nano, Malvern). Thus, from the light scattering measurements, we demonstrate that the luminescence quenching caused by $\mathrm{H}_{2} \mathrm{O}_{2}$ is not through the aggregation of the 11-MUA-Au NDs.

The properties of our luminescent 11-MUA-Au NDs have been studied by high resolution transmission electron microscopy (HRTEM), UV-vis absorption spectrometry, fluorescence spectrometry, luminescence lifetime spectrometry, energy-dispersive X-ray spectroscopy (EDS), X-ray photoelectron spectroscopy (XPS) and static light scattering experiments. ${ }^{5}$ Our luminescent 11-MUA-Au NDs had large Stokes-shifted luminescence $(>1.0 \mathrm{eV})$ with long lifetimes $\left(\tau_{1} / \tau_{2}\right)$ of $36 / 231$ ns (curve A, Fig. S1 + ), which are general characteristics of thiol-Au(I) complexes that display ligand-metal charge transfer and metal(I)-metal(I) interactions. ${ }^{6,7}$ Furthermore, the lifetimes of the 11-MUA-Au NDs decrease to $1.3 / 53.4 \mathrm{~ns}\left(\tau_{1} / \tau_{2}\right)$ in the presence of $10 \mathrm{mM}$ $\mathrm{H}_{2} \mathrm{O}_{2}$ (curve $\mathrm{B}$, Fig. $\mathrm{S} 1 \dagger$ ), which further demonstrate that their luminescence is highly dependent on their surface environmental properties. Also, similarly to the optical properties of thiol-Au(I) complexes, the luminescence intensity of the 11-MUA-Au NDs (10 nM) decreases 4.5-fold upon addition $\mathrm{NaBH}_{4}$ and increases up to 4.0-fold at liquid nitrogen temperature $(77 \mathrm{~K})$, respectively (Fig. S2 $\dagger){ }^{6-8}$ Thus, we suspect that the luminescence of our 11-MUA-Au NDs mainly originated from $\mathrm{Au} \mathrm{ND} /$ polynuclear $\mathrm{Au}(\mathrm{I})$-thiol

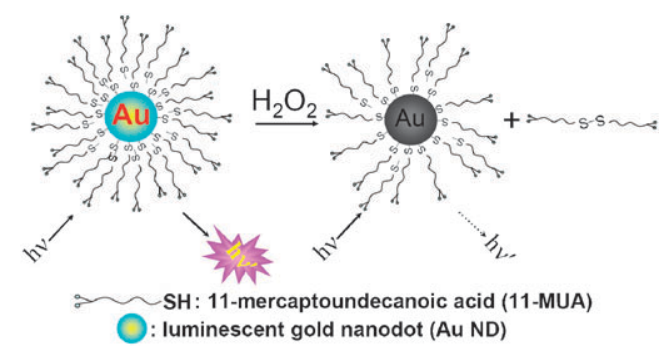

Scheme 1 Schematic representation of an $\mathrm{H}_{2} \mathrm{O}_{2}$ nanosensor that operates through a mechanism based on the modulated luminescence quenching of 11-MUA-Au NDs. $h$ : Planck's constant; $\nu$ : frequency of light. 


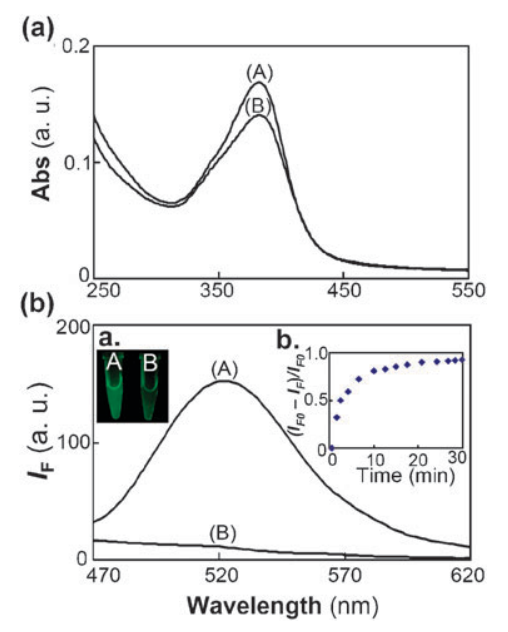

Fig. 1 (a) UV-vis absorption and (b) luminescence spectra of the 11-MUA-Au NDs in the (A) absence and (B) presence of $\mathrm{H}_{2} \mathrm{O}_{2}$. The luminescence intensities $\left(I_{\mathrm{F}}\right)$ are plotted in arbitrary units (a. u.); excitation wavelength: $375 \mathrm{~nm}$. First inset to Fig. 1b: photograph displaying the luminescence of the 11-MUA-Au NDs in the (A) absence and (B) presence of $\mathrm{H}_{2} \mathrm{O}_{2}$ upon excitation ( $365 \mathrm{~nm}$ ) under a hand-held UV lamp. Second inset to Fig. 1b: plot of the relative luminescence $\left[\left(I_{\mathrm{F} 0}-I_{\mathrm{F}}\right) / I_{\mathrm{F} 0}\right]$ over time of the intensity at $520 \mathrm{~nm}$ of the 11-MUA-Au NDs after the addition of $\mathrm{H}_{2} \mathrm{O}_{2}$, where $I_{\mathrm{F} 0}$ and $I_{\mathrm{F}}$ are the luminescence intensities of the 11-MUA-Au NDs in the absence and presence of $\mathrm{H}_{2} \mathrm{O}_{2}$, respectively.

(core/shell) complexes. ${ }^{9,10}$ Thus, the luminescence intenity of 11-MUA-Au NDs is higly effected by the density of 11-MUA on the surface of the Au NDs. ${ }^{10}$

To support our quenching mechanism proposed in Scheme 1, we used zeta potential, TEM and XPS measurements to characterize the surface properties of the 11-MUA-Au NDs in the absence and presence of $\mathrm{H}_{2} \mathrm{O}_{2}$ (Fig. S3 and $\mathrm{S} 4 \dagger$ ). We confirmed the impact that the surface 11-MUA molecules have on the luminescence changes in the 11-MUA-Au NDs by adding various amounts of 11-MUA (0-1.0 mM) into 11-MUA-Au ND (100 nM) solutions that had been reacted with $10 \mathrm{mM} \mathrm{H} \mathrm{H}_{2} \mathrm{O}_{2}$. The luminescence of the mixtures increased upon increasing the concentration of 11-MUA, reaching a plateau at $1.0 \mathrm{mM}$ (Fig. S5a $\dagger$ ). The phenomenon of restored luminescence reveals that new 11-MUA molecules were bound to the 11-MUA-Au NDs. To test whether our sensor could be reused, we recorded the luminescence of the 11-MUA-Au ND solution after adding $\mathrm{H}_{2} \mathrm{O}_{2}$ and 11-MUA 10 times alternately and repeatedly. Fig. S5b indicates the good reproducibilities of the luminescence quenching. $\dagger$

To test the possibility of using our 11-MUA-Au NDs for the detection of $\mathrm{H}_{2} \mathrm{O}_{2}$, we investigated the effects of the solution $\mathrm{pH}$ and temperature on the luminescence intensity. The plot of the luminescence intensities $\left(I_{\mathrm{F} 0}\right)$ of the 11-MUA-Au NDs (10 nM) in the absence of $\mathrm{H}_{2} \mathrm{O}_{2}$ at various values of $\mathrm{pH}$ (Fig. S6a $\dagger$ ) reveals that the luminescence reached a maximum at $\mathrm{pH} 5.0$ and gradually decreased upon increasing the $\mathrm{pH}$ values from 5.0 to 11.0 . In contrast, the luminescence intensities $\left(I_{\mathrm{F}}\right)$ changed to a lesser extent in the presence of $1.0 \mathrm{mM} \mathrm{H}_{2} \mathrm{O}_{2}$ (Fig. S6a $\dagger$ ). The reason for these different $\mathrm{pH}$ effects on the change in luminescence remains unclear, but we suspect that changes in surface density due to the dissociation of 11-MUA units is one possible explanation. The values of $\mathrm{p} K_{\mathrm{a} 1}$ (carboxyl group) and $\mathrm{p} K_{\mathrm{a} 2}$ (sulfhydryl group) of 11-MUA are $c a .5 .7$ and $c a$. 8.9, respectively. ${ }^{11}$ Because of the increased solubility of 11-MUA in aqueous solution upon increasing the $\mathrm{pH}$ values, we suspect that the release of 11-MUA units bound to the $\mathrm{Au}$ NDs through weaker nonspecific binding (hydrophobic or hydrogen-bonding interactions) into the bulk solution is another possible explanation. In addition, changes in the stability of MUA-Au(I) complexes and the hydroxyl ion $\left(\mathrm{HO}^{-}\right)$-induced luminescence quenching of 11-MUA-Au NDs should not be ruled out. ${ }^{5}$ The slight degree of aggregation of the 11-MUA-Au NDs was the main reason for the low luminescence intensity at $\mathrm{pH}$ 4.0. Because the solution $\mathrm{pH}$ has a different effect on the luminescence of the 11-MUA-Au NDs in the absence and presence of $\mathrm{H}_{2} \mathrm{O}_{2}$, we plotted the relative luminescence $\left[\left(I_{\mathrm{F} 0}-I_{\mathrm{F}}\right) / I_{\mathrm{F} 0}\right]$ of the 11-MUA-Au NDs against the $\mathrm{pH}$ (Fig. S6a $\dagger$ ) to determine that a $\mathrm{pH}$ of 5.0 provided the optimal sensitivity. Next, we examined the luminescence of the 11-MUA-Au NDs in the absence and presence of $\mathrm{H}_{2} \mathrm{O}_{2}$ $(1.0 \mathrm{mM})$ over the temperature range from 25 to $75^{\circ} \mathrm{C}$. The trend in the plot of $\left(I_{\mathrm{F} 0}-I_{\mathrm{F}}\right) / I_{\mathrm{F} 0}$ for the 11-MUA-Au NDs against the temperature (Fig. S6b $\dagger$ ) reveals that the sensor performed better at high temperature, reaching a maximum at $65^{\circ} \mathrm{C}$.

Under the optimal conditions-11-MUA-Au NDs (10 nM) in sodium phosphate solution ( $10 \mathrm{mM}, \mathrm{pH} 5.0)$ at an incubation temperature of $65{ }^{\circ} \mathrm{C}$-we used our sensor to determine the concentrations of $\mathrm{H}_{2} \mathrm{O}_{2}$ in solution. Fig. 2 reveals that the luminescence intensity of the mixtures decreased linearly $\left(R^{2}=0.96\right)$ upon increasing the concentration of $\mathrm{H}_{2} \mathrm{O}_{2}$ over the range $100 \mathrm{nM}-1.0 \mathrm{mM}$. The limit of detection (LOD) for $\mathrm{H}_{2} \mathrm{O}_{2}$ was $30 \mathrm{nM}$, based on a signal-to-noise ratio $(\mathrm{S} / \mathrm{N})$ of 3 ; these values are comparable with those obtained using other optical $\mathrm{H}_{2} \mathrm{O}_{2}$ sensors. ${ }^{2}$ Our five-order linear relationship between the luminescence signal and the $\mathrm{H}_{2} \mathrm{O}_{2}$ concentration is much wider than those of most other reported sensor systems based on analyte-induced aggregation of nanomaterials. ${ }^{12}$

The good sensitivity and wide linearity of the detection of $\mathrm{H}_{2} \mathrm{O}_{2}$ suggested that the 11-MUA-Au NDs would hold great

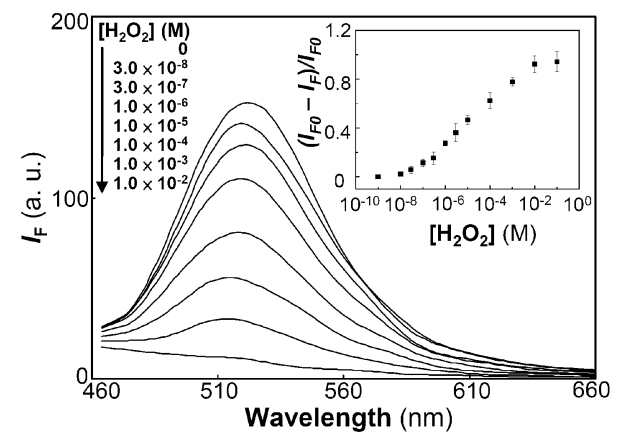

Fig. 2 Luminescence responses of the 11-MUA-Au NDs after the addition of $\mathrm{H}_{2} \mathrm{O}_{2}(0-10 \mathrm{mM})$. Inset: Plot of the luminescence ratio $\left[\left(I_{\mathrm{F} 0}-I_{\mathrm{F}}\right) / I_{\mathrm{F} 0}\right]$ of the 11-MUA-Au NDs at $520 \mathrm{~nm}$ versus the $\log$ concentration of $\mathrm{H}_{2} \mathrm{O}_{2}$. The error bars represent the standard deviation of three repeated measurements. Other conditions were the same as described in Fig. 1. 


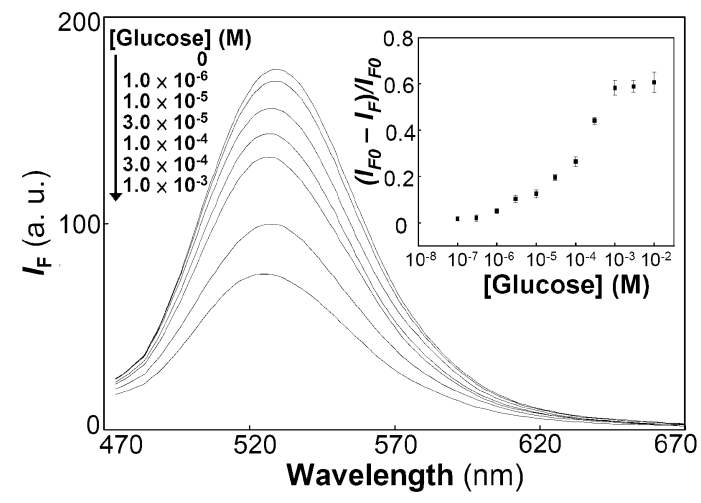

Fig. 3 Validation of the 11-MUA-Au ND sensor for the detection of glucose $(0-10 \mathrm{mM})$. Inset: plot of the luminescence ratio $\left[\left(I_{\mathrm{F} 0}-I_{\mathrm{F}}\right) / I_{\mathrm{F} 0}\right]$ of the 11-MUA-Au NDs at $520 \mathrm{~nm}$ versus the log concentration of glucose. Error bars represent the standard deviation of three repeated experiments.

potential for use in the determination of glucose. Because the activity of glucose oxidase (GOx) is not optimal at pH 5.0 and $65{ }^{\circ} \mathrm{C}$, we conducted a two-step analysis process: first, glucose and GOx were reacted in sodium phosphate solutions $(10 \mathrm{mM}$, $\mathrm{pH} 7.0$ ) at $37{ }^{\circ} \mathrm{C}$ for $5 \mathrm{~min}$; next, the produced $\mathrm{H}_{2} \mathrm{O}_{2}$ was detected using the 11-MUA-Au NDs at pH 5.0 and $65{ }^{\circ} \mathrm{C}$. Fig. 3 displays the linear response $\left(R^{2}=0.95\right)$ of the luminescence plotted against the logarithm of the concentration of glucose over the range $30 \mu \mathrm{M}-1.0 \mathrm{mM}$. The limit of detection (LOD) of this sensor for glucose was $1.0 \mu \mathrm{M}$, comparable to those obtained using electrochemical methods. ${ }^{13}$

Next, we tested the specificity of 11-MUA-Au ND nanosensor by conducting several control experiments using maltose, lactose, fructose, galactose, and mannose. We did not observes any changes in the luminescence spectra of the 11-MUA-Au NDs (10 nM) in the absence of GOx after separately adding $1.0 \mathrm{mM}$ of the five carbohydrates. In the presence of GOx, however, our sensor system responded selectivity toward glucose over maltose, lactose, fructose, galactose, and mannose by factors of 33, 104, 5.9, 31, and 2.2 , respectively (Fig. $\mathrm{S} 7 \dagger$ ). The activities of a commercial GOx for glucose, mannose, lactose, and maltose were 1413, 1095, 92, 665 unit, respectively. ${ }^{14}$ We point out that the concentration of glucose in blood samples is higher than all other carbohydrates by a factor of 100 -fold. ${ }^{15}$ In other words, interference from other carbohydrates in the determination of glucose by our nanosensor can be ignored. The interference of the sensor system from some thiol compounds (cysteine, homocysteine, glutathione) and protein (BSA) was also tested. The relative luminescence $\left[\left(I_{\mathrm{F} 0}-I_{\mathrm{F}}\right) / I_{\mathrm{F} 0}\right]$ of $11-\mathrm{MUA}-\mathrm{Au}$ NDs $(10 \mathrm{nM})$ for the detection of $\mathrm{H}_{2} \mathrm{O}_{2}(10 \mathrm{mM})$ in the absence and presence of the interferences $(50 \mu \mathrm{M})$ have no obvious differences (Fig. S $8 \dagger$ ). We point out that the concentrations of the three aminothiols in serum were lower than $50 \mu \mathrm{M} .^{16}$ To demonstrate the potential practicality of our sensor system, we determined glucose in blood samples after spiking them with standard glucose solutions (0-1.0 mM; Fig. S9 $\dagger)$. We determined the concentration of glucose in one of the serum samples to be $3.9 \mathrm{mM}$, in good agreement with that $(4.3 \mathrm{mM})$ determined using a commercial blood glucose electrochemical analysis system
(Abbott Laboratories, Alameda, CA, USA). The F-test value was 1.5 for our sensor system $(n=5)$, with the F-test value being 6.39 at a $95 \%$ confidence level, revealing that the two methods provided essentially identical results. The recoveries of these measurements were $94-98 \%$. Our results suggest that this probe has great potential for use in determining biological relevant concentrations of glucose.

In conclusion, we have developed an assay system containing water-soluble 11-MUA-Au NDs for the quantitative determination of $\mathrm{H}_{2} \mathrm{O}_{2}$ and, vicariously, for glucose. The assay is quite insensitive to matrix interference when determining glucose, mainly because of its intrinsic large Stokes shift. Under the optimal conditions, the sensitivity of the 11-MUA-Au ND sensing system toward glucose was high $(\mathrm{LOD}=1.0 \mu \mathrm{M})$ in aqueous solution, with good selectivity over other carbohydrates. Relative to other standard glucose assays, our 11-MUA-Au ND nanosensor exhibits several practical advantages, including the ease of reagent preparation, wider linearity, and a lower degree of sample matrix interference. Although we have demonstrated only the determination of glucose in this study, this sensing strategy could be applied further to determine many other analytes, such as uric acid, lactate, glutamate, and cholesterol, when performed in conjunction with suitable enzymes.

We are grateful to the National Science Council of Taiwan for providing financial support to this study under contracts NSC 95-2113-M-002-026-MY3, NSC 97-2627-M-002-010, NSC 97-2627-M-002-011 and 97-2113-M-019-001-MY2.

\section{Notes and references}

1 (a) M. Drábková, W. Admiraal and B. Maršálek, Environ. Sci. Technol., 2007, 41, 309-314; (b) L. B. Poole and K. J. Nelson, Curr. Opin. Chem. Biol., 2008, 12, 18-24.

2 B. C. Dickinson and C. J. Chang, J. Am. Chem. Soc., 2008, 130, 9638-9639.

3 J. L. Lyon and K. J. Stevenson, Anal. Chem., 2006, 78, 8518-8525.

4 (a) A. R. Quesada, R. W. Byrnes, S. O. Krezoski and D. H. Petering, Arch. Biochem. Biophys., 1996, 334, 241-250; (b) M. Dasog and R. W. J. Scott, Langmuir, 2007, 23, 3381-3387.

5 (a) C.-C. Huang, Z. Yang, K.-H. Lee and H.-T. Chang, Angew. Chem., Int. Ed., 2007, 46, 6824-6828; (b) C.-C. Huang, C.-K. Chiang, Z.-H. Lin, K.-H. Lee and H.-T. Chang, Anal. Chem., 2008, 80, 1497-1504; (c) C.-C. Huang, H.-Y. Liao, Y.-C. Shiang, Z.-H. Lin, Z. Yang and H.-T. Chang, J. Mater. Chem., 2009, 19, 755-759.

6 V. W.-W. Yam and E. C.-C. Cheng, Chem. Soc. Rev., 2008, 37, $1806-1813$.

7 A. Vogler and H. Kunkely, Coord. Chem. Rev., 2001, 219-221, 489-507.

8 H. Duan and S. Nie, J. Am. Chem. Soc., 2007, 129, 2412-2413.

9 Y. Negishi and T. Tsukuda, Chem. Phys. Lett., 2004, 383, 161-165.

10 (a) R. L. Whetten and R. C. Price, Science, 2007, 318, 407-408; (b) G. Wang, R. Guo, G. Kalyuzhny, J.-P. Choi and R. W. Murray, J. Phys. Chem. B, 2006, 110, 20282-20289.

11 J. F. Smalley, K. Chalfant, S. W. Feldberg, T. M. Nahir and E. F. Bowden, J. Phys. Chem. B, 1999, 103, 1676-1685.

12 R. Wilson, Chem. Soc. Rev., 2008, 37, 2028-2045.

13 J.-J. Xu, J.-J. Feng, X. Zhong and H.-Y. Chen, Electroanalysis, 2008, 20, 507-512.

14 M. Kobayashi, H. Nishara and S. Kobayashi, J. Appl. Glycosci., 1999, 46, 1-7.

15 T. Kawasaki, H. Akanuma and T. Yamanouchi, Diabetes Care, 2002, 25, 353-357.

16 C. Carru, A. Zinellu, S. Sotgia, R. Serra, M. F. Usai, G. F. Pintus, G. M. Pes and L. Deiana, Biomed. Chromatogr., 2004, 18, 360-366. 